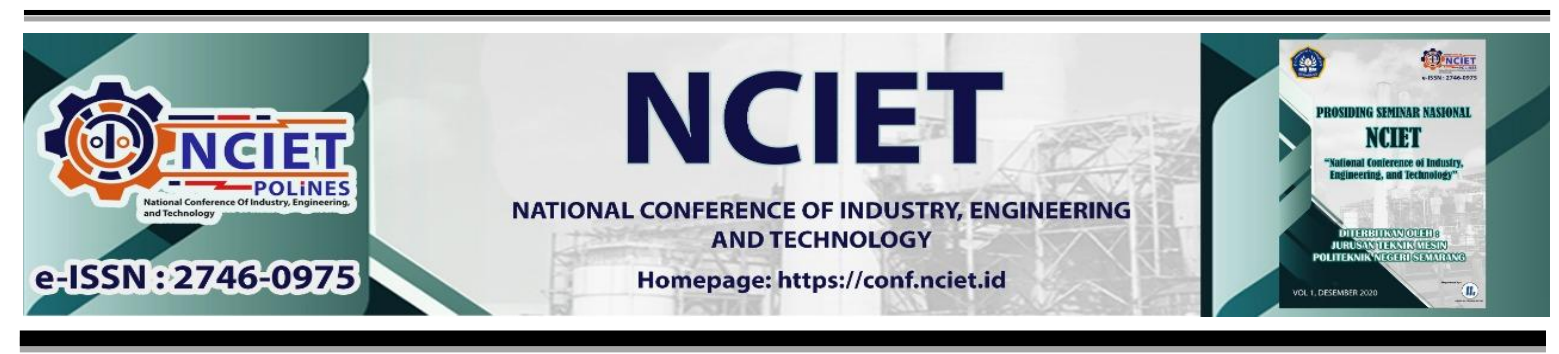

Prosiding Seminar Nasional NCIET Vol.1 (2020) B301-B311

$1^{\text {st }}$ National Conference of Industry, Engineering and Technology 2020,

Semarang, Indonesia.

\title{
PENGUJIAN KINERJA RELAY INVERSE TIME OVERCURRENT 3 PHASA UNTUK MENUNJANG PRAKTIKUM SISTEM PROTEKSI
}

\section{Wahyono*, Wiwik Purwati Widyaningsih, dan Ajie Pribadi N, Choirul Nur H, Fidiyan Kelfin M, Fitri Shafira}

\author{
Jurusan Teknik Mesin, Politeknik Negeri Semarang \\ J1. Prof. H. Soedarto S.H., Tembalang, Semarang, 50275 \\ *E-mail: wahyono.polines@gmail.com
}

\begin{abstract}
Abstrak
Over Current Relay merupakan salah satu alat sistem proteksi pada jaringan listrik. Over Current Relay bekerja berdasarkan adanya kenaikan arus gangguan yang melebihi suatu nilai pengaman tertentu dan jangka waktu tertentu. Jenis relay yang akan digunakan dalam pengujian ini adalah NX203A IDMT Over Current Relay. Tujuan pengujian ini yaitu untuk mendapatkan modul praktikum yang baik dan untuk membuktikan kurva karakteristik relay inverse time sesuai dengan British Standart BS142. Dalam pengujiannya, alat yang akan dirakit diuji fungsi kerjanya sehingga dalam pengambilan data kesalahan dapat dihindari sedangkan relay pada modul akan diberi arus setting sebesar 2A; 3A; dan 4A dengan TMS 0,05; 0,5; dan 1,0 yang akan dihubungkan dengan timer digital sehingga apabila arus gangguan melebihi arus settingnya maka secara otomatis relay memberi sinyal dan timer digital akan menunjukkan waktu terputusnya arus. Hasil akhir berupa modul praktikum yang setiap alatnya berfungsi dalam keadaan normal untuk bekerja dan grafik waktu terhadap arus relay untuk arus setting 2A, waktu tercepat yaitu 0,498 s pada arus gangguan 9A dan TMS 0,05, waktu terlama yaitu 12 , 991s pada arus gangguan 4A TM 1,0. Arus setting 3A untuk waktu tercepat yaitu $0,572 \mathrm{~s}$ pada arus gangguan 9A dan TM 0,05, untuk waktu terlama yaitu 35,854 s pada arus gangguan 4A dan TM 1,0. Arus setting 4A untuk waktu tercepat yaitu $0,708 \mathrm{~s}$ pada arus gangguan 9A dan TM 0,05, untuk waktu terlama yaitu 55,979s pada arus gangguan 5A dan TM 1,0.
\end{abstract}

Kata Kunci: Inverse Time Over Current Relay

\section{PENDAHULUAN}

Sistem proteksi mempunyai peranan penting dalam pengoperasian sistem tenaga listrik saat terjadi gangguan. Gangguan tersebut dapat berasal dari gangguan luar maupun gangguan dalam. Gangguan luar ialah gangguan yang disebabkan karena gejala alam seperti cuaca, banjir, gempa bumi, dan sambaran petir sedangkan gangguan dari dalam ialah gangguan yang disebabkan kerusakan pada sistem seperti faktor manusia (human error), usia pakai komponen yang sudah lama, tegangan dan arus abnormal, beban lebih, serta kerusakan isolator. Relay adalah alat yang mengamankan sistem tenaga listrik dengan 
cara mendeteksi adanya gangguan yang terjadi pada jaringan. Apabila terjadi gangguan maka relay akan memberikan perintah pada pemutus tenaga untuk memutuskan arus yang menyebabkan gangguan tersebut. Relay pengaman dapat mengetahui adanya gangguan pada peralatan jaringan listrik dengan mengukur atau membandingkan besaran besaran yang diterima misalnya besaran tegangan, arus, daya, frekuensi dan lainnya.

Over Current Relay (Relay arus lebih) adalah relay yang bekerja berdasarkan adanya kenaikan arus yang melebihi suatu nilai pengaman tertentu dan jangka waktu tertentu. Over Current Relay adalah relay yang bekerja terhadap arus lebih, ia akan bekerja bila arus yang mengalir melebihi nilai settingnya (Iset). Over Current Relay bekerja berdasarkan adanya arus lebih yang dirasakan relay, baik disebabkan adanya gangguan hubung singkat ataupun beban lebih untuk kemudian memberikan perintah trip ke PMT sesuai dengan karakteristik waktunya.

Pada perakitan modul praktikum ini menggunakan NX203A IDMT Over current relay. IDMT (Inverse Definite Minimum Time) merupakan tipe karakteristik kurva proteksi yang digunakan dalam menentukan parameter proteksi. Kata inverse berarti semakin tinggi arus gangguan yang terdeteksi melewati suatu sistem yang diproteksi, maka semakin cepat waktu dari relay proteksi tersebut untuk memerintahkan agar Circuit Breaker bekerja untuk memutuskan (trip) sistem. Nilai arus dan waktu trip pada relay proteksi sangat bervariasi, sesuai dengan karakteristik beban dan jaringan yang akan dilindungi sehingga terjadinya gangguan pada salah satu titik pada sebuah jaringan tenaga listrik tidak akan menyebabkan gangguan secara total.

Relay inverse time mempunyai 3 jenis kurva karakteristik yaitu:

1. Standart Inverse (SI)

Kurva Standart Inverse yaitu bentuk kurva Over Current Relay dengan penundaan waktu terbalik yang pendek.

2. Very Inverse (VI)

Kurva Very Inverse yaitu bentuk kurva Over Current Relay dengan penundaan waktu terbalik yang sangat lama bila dibanding dengan Standart Inverse.

3. Extreme Inverse (EI)

Kurva Extreme Inverse yaitu bentuk kurva Over Current Relay dengan penundaan waktu terbalik yang amat sangat lama daripada Very Inverse maupun Standart Inverse. 
Berdasarkan tujuan penulisan tugas akhir ini, adapun rumusan masalah pada pembahasan mengenai bagaimana hasil perakitan modul praktikum Relay arus lebih dan hasil pengujian kurva karakteristik Inverse time Over current Relay?

Dalam Pengujian ini dilakukan analisis perhitungan besar arus gangguan yang digunakan dengan cara sebagai berikut:

Penentuan besaran arus gangguan yang diberikan pada sistem dilakukan dengan panduan yang tertera dalam manual book IDMT Over Current Relay NX203A .

a. Penyesuaian Arus Set Rendah Berlebih (l>)

Penyesuaian ini untuk menyetel arus lebih minimum untuk mengetrip dengan penundaan waktu.

Rentang pengaturan adalah dari 2A hingga $6 \mathrm{~A}$.

Rentang pengaturan adalah dari $1 \mathrm{x}$ hingga $10 \mathrm{x}$ arus lebih nilai pengaturan rendah.

$$
\frac{\mathrm{I}}{\mathrm{I}}=\mathrm{a}
$$

Keterangan :

$\mathrm{I} \quad=$ Arus gangguan (Ampere)

$\mathrm{I}>=$ Arus setting rendah (Ampere)

$\mathrm{a} \quad=$ Arus nominal (1 sampai 10)

b. Penyesuaian Time Multiplier (TM)

- Pengganda waktu untuk menyetel waktu normal terbalik / karakteristik saat ini (IDMT) sesuai dengan BS142.

- Rentang pengaturan adalah dari 0,05 hingga 1,0

\section{METODE PENELITIAN}

Perencanaan pembuatan tugas akhir ini diawali dengan kurang beragamnya jenis relay pengaman yang digunakan dalam praktikum sistem proteksi di Laboratorium Teknik Konversi Energi, dengan menambahkan peralatan relay arus lebih sehingga mahasiswa dapat menggunakan modul ini sebagai bahan praktikum di Laboratorium Teknik Konversi Energi.

1) Penelusuran Literatur

Metode ini dilakukan dengan cara menelusuri dan mempelajari buku - buku serta mencari informasi tentang relay arus lebih melalui media cetak maupun media online.Penelusuran literatur memperhitungkan beberapa aspek meliputi fungsi alat, cara kerja alat, biaya 
pembuatan, estetika modul, dan berbagai aspek lainnya dengan sumber data yang valid dan benar.

2) Perancangan Modul

Proses pembuatan modul didahului dengan perencanaan bentuk modul yang dibuat dengan software inventor, adapun bagian yang dirancang yaitu boks modul, penyangga boks, tata letak alat yang akan dirakit.Perancangan diagram Pengawatan dibuat dengan software micorosoft visio.

3) Perakitan Modul

Proses perakitan adalah proses penyatuan semua alat untuk dijadikan satu sistem dengan tujuan tertentu.Tahapan ini diawali dengan persiapan alat dan bahan yang akan digunakan seperti Over current relay, Timer digital,Voltmeter,Amperemeter, MCB, dan akrilik. Proses selanjutnya yaitu pembuatan boks yang diawali dengan mengkur panjang, lebar, serta tinggi yang dibutuhkan sesuai perancangan, Penyangga boks dibuat sesuai dengan perancangan. Tahap selanjutnya yaitu menyambungkan semua alat dan bahan menjadi 1 unit sistem.

\section{4) Pengujian Modul}

Prosedur pengujian dilakukan dengan menguji hasil perakitan modul terlebih dahulu agar bekerja sesuai dengan fungsinya.Pengujian selanjutnya yaitu pengujian karakteristik relay dengan cara relay di setting pada arus setting tertentu kemudian pada rangkaian pengujian diberikan arus gangguan yang besarnya melebihi arus setting.Pengujian ini dilakukan dengan beberapa variasi arus setting, arus gangguan, dan time multiple setting.Parameter yang diukur dalam pengujian ini meliputi Arus setting (Ampere), Arus gangguan (Ampere), Waktu trip (sekon), Tegangan (volt) dan keadaan relay.

\section{HASIL DAN PEMBAHASAN}

Tabel 1 Hasil Pengujian Alat yang dirakit

\begin{tabular}{|c|c|c|c|c|}
\hline No & Bagian & Masalah & Solusi & Hasil \\
\hline 1. & Boks Modul praktikum & - & - & Baik \\
\hline 2. & Penyangga Boks & - & - & Baik \\
\hline 3. & NX203A Overcurrent relay & - & - & Baik \\
\hline 4. & Timer H5CZ & - & - & Baik \\
\hline 5. & Voltmeter & - & - & Baik \\
\hline 6. & Amperemeter & - & - & Baik \\
\hline 7. & MCB 1 Phasa & - & - & Baik \\
\hline
\end{tabular}


Berdasarkan hasil pengujian Modul praktikum yang dilakukan semua alat yang dirakit dapat bekerja dengan baik sehingga dapat disimpulkan bahwa modul praktikum dapat digunakan sesua dengan fungsi kerjanya.

1. Grafik Pengujian Karakteristik Invers Time Over current relay

1.Kurva karakteristik relay inverse time over current dengan arus setting $2 \mathrm{~A}$

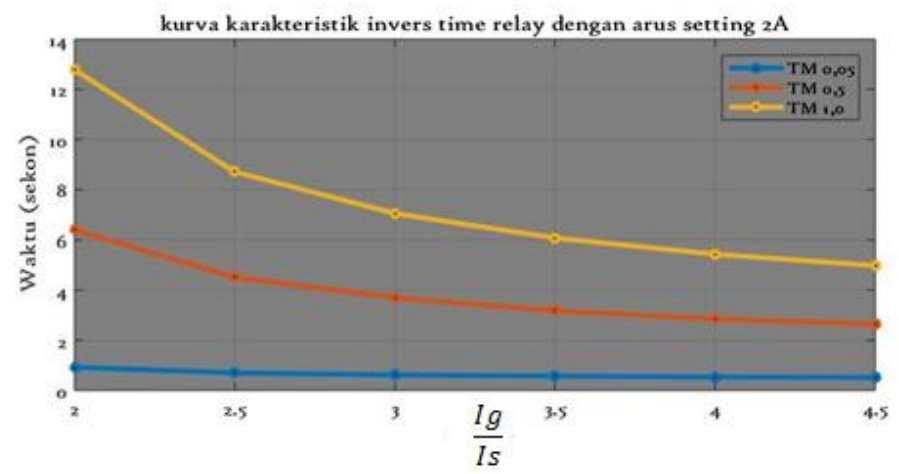

Gambar 1 kurva karakteristik relay inverse time over current Arus Setting 2A Line "R"

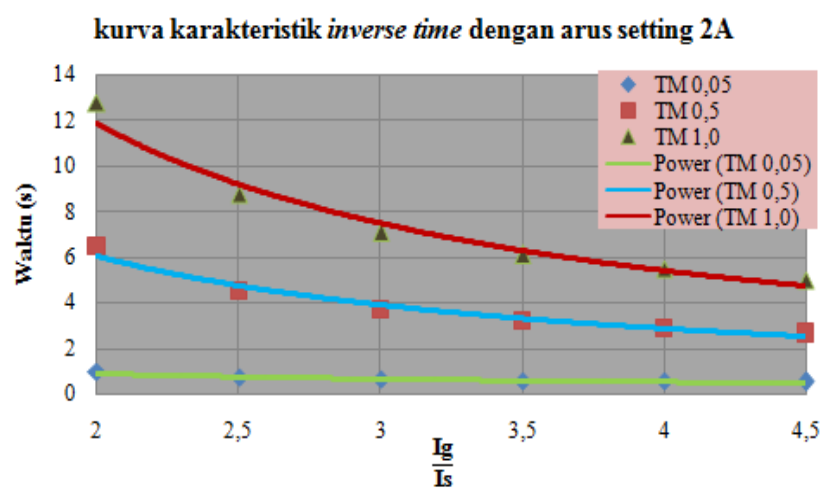

Gambar 2 Kurva karakteristik relay inverse time over currentArus setting 2A Line "R" dengan garis trendline

Berdasarkan grafik yang telah digambarkan nampak bahwa semakin besar nilai arus gangguan maka waktu tripping relay akan semakin cepat. Terlihat juga bahwa apabila diberi arus gangguan yang sama tetapi setting waktu semakin besar maka waktu tripping akan semakin lambat.Garis trendline yang digambarkan nampak bahwa garis data percobaan dengan garis trendline hampir sama, sehingga grafik pada teori dapat dibuktikan dengan grafik data percobaan. Untuk setting waktu TM 0,05s bentuk kurva sangat landai dan waktu mendekati angka nol,ini merupakan karakteristik relay inverse time over current dengan kurva Standart Inverse. Selanjutnya nilai setting waku dinaikkan menjadi 0,5s sehingga waku tripping relay menjadi agak lambat daripada setting waktu 0,05 s,ini dinamakan dengan karakteristik relay inverse time over curren tkurva Very Inverse. 
Kemudian setting waktu dibuat maksimum yaitu 1,0s dan menghasilkan kurva yang waktu tripping relay menjadi sangat lambat,ini dinamakan dengan karakteristik relay inverse time over current kurva Extreme Inverse.

2.Kurva karakteristik relay inverse time over current dengan arus setting $3 \mathrm{~A}$

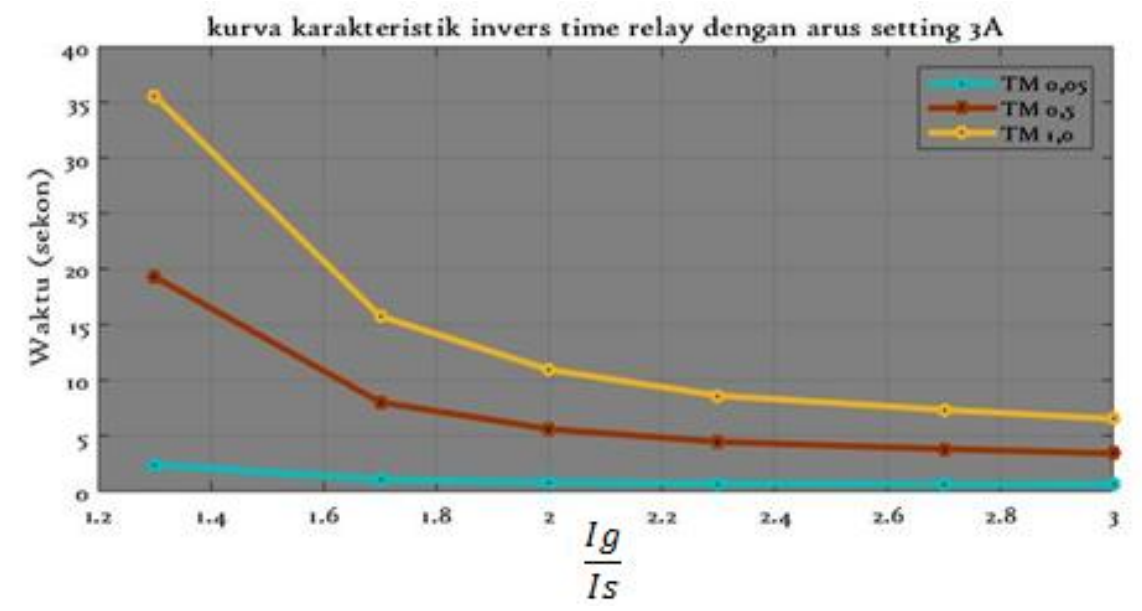

Gambar 3 Kurva karakteristik relay inverse time over current Arus Setting 3A Line "R"

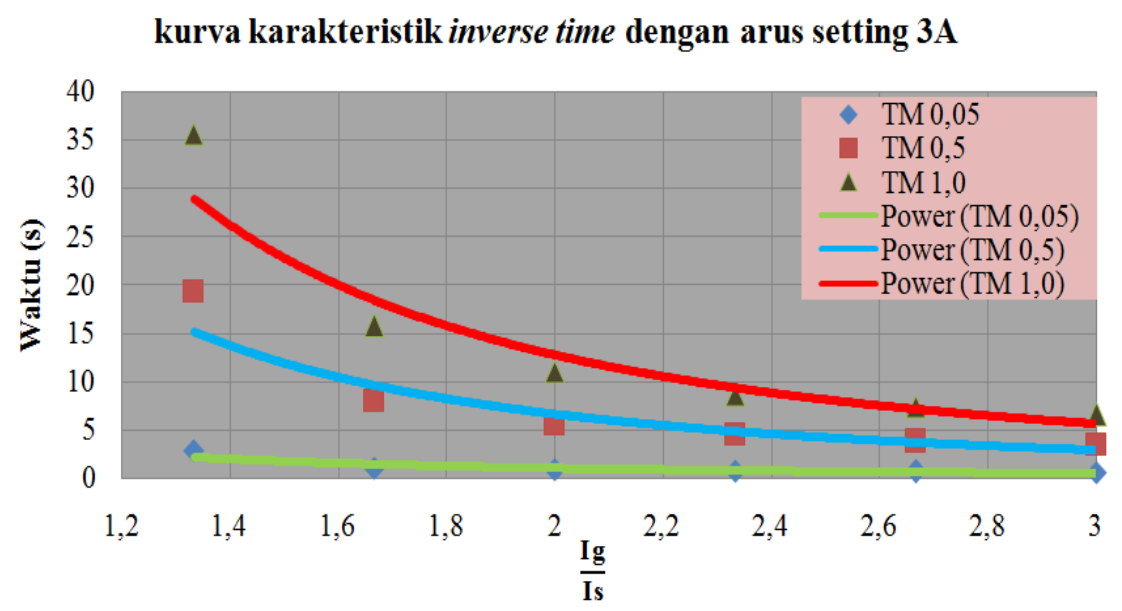

Gambar 4 Kurva karakteristikrelay inverse time over current arus setting 3A Line "R" dengan trendline

Berdasarkan grafik yang telah digambarkan nampak bahwa semakin besar nilai arus gangguan maka waktu tripping relay akan semakin cepat. Terlihat juga bahwa apabila diberi arus gangguan yang sama tetapi setting waktu semakin besar maka waktu tripping akan semakin lambat.Garis trendline yang digambarkan nampak bahwa garis data percobaan dengan garis trendline terdapat beberapa perbedaan yang dikarenakan garis trendline merupakan garis yang berfungsi untuk memperhalus bentuk kuva. Untuk setting waktu TM 0,05s bentuk kurva sangan landai dan waktu mendekati angka nol,ini merupakan karakteristik relay inverse time over current dengan kurva Standart Inverse. 
Selanjutnya nilai setting waku dinaikkan menjadi $0,5 \mathrm{~s}$ sehingga waku tripping relay menjadi agak lambat daripada setting waktu 0,05 s,ini dinamakan dengan karakteristik relay inverse time over currentrse time relay kurva Very Inverse. Kemudian setting waktu dibuat maksimum yaitu 1,0s dan menghasilkan kurva yang waktu tripping relay menjadi sangat lambat,ini dinamakan dengan karakteristik relay inverse time over current kurva Extreme Inverse.

3.Kurva Karakteristik relay inverse time over current dengan arus setting 4A

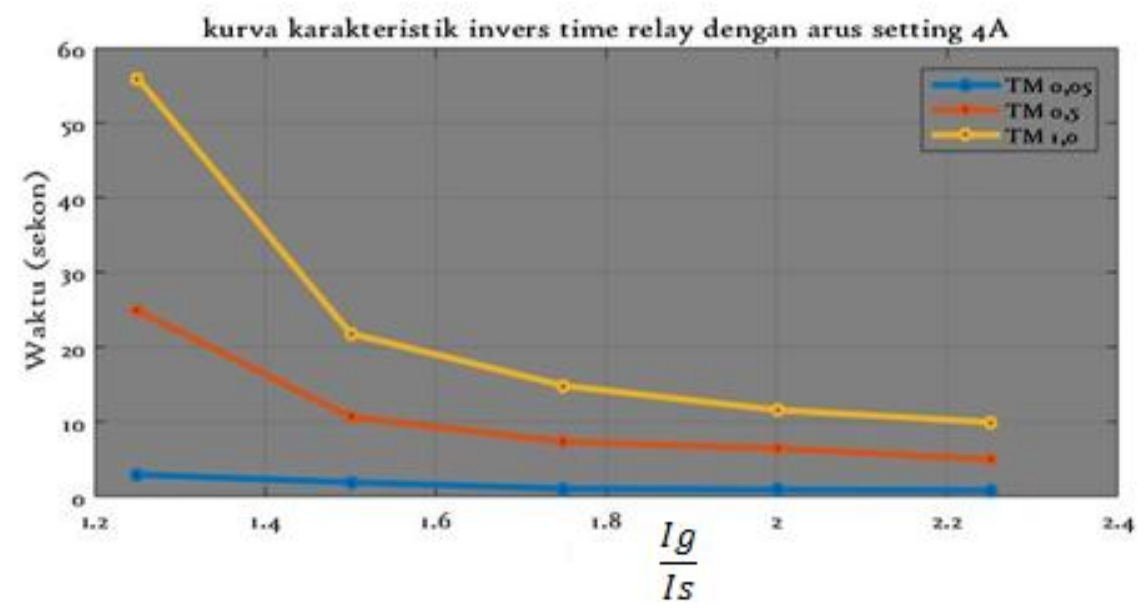

Gambar 5 Kurva karakteristik relay inverse time over current Arus Setting 4A Line "R" kurva karakteristik inverse time dengan arus setting $4 \mathrm{~A}$

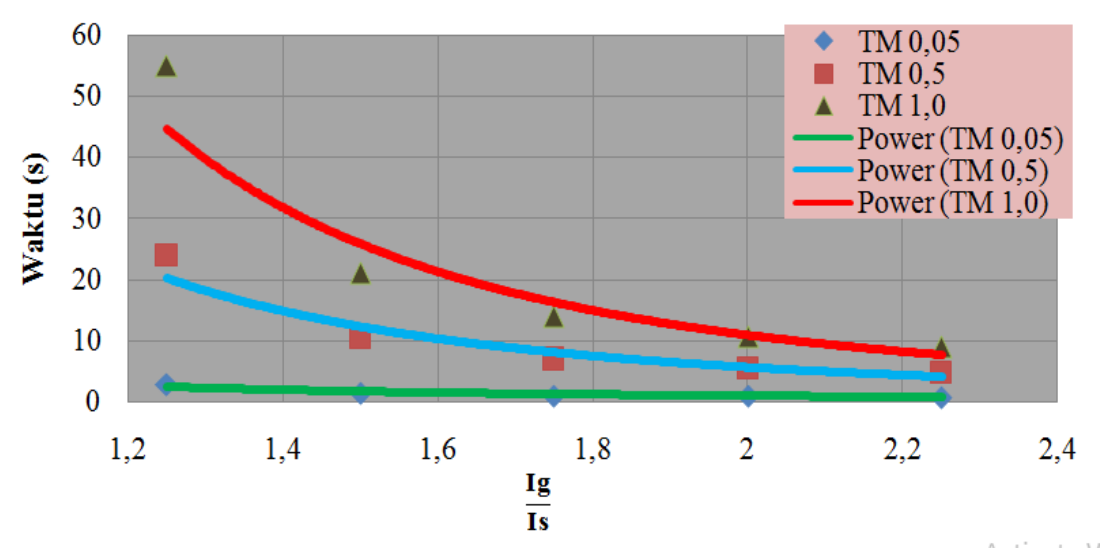

Gambar 6 Kurva karakteristik relay inverse time over current Arus Setting 4A Line "R" dengan trendline

Grafik Relay ini menggambarkan untuk setiap arus setting yang sama tetapi diberi arus gangguan dan setting waktu yang berbeda akan menghasilkan kurva yang berbeda, terdapat tiga kurva yang berbeda,tetapi persamaan dari ketiga kurva diatas yaitu memiliki karakteristik yang sama, semakin besar nilai arus gangguan maka semakin kecil waktu tripping yang dibutuhkan untuk membuat relay bekerja sehingga arus gangguan yang lewat 
di sistem dapat diamankan. Untuk setting waktu TM 0,05s bentuk kurva sangat landai dan waktu mendekati angka nol,ini merupakan karakteristik relay inverse time over current dengan kurva Standart Inverse.Selanjutnya nilai setting waku dinaikkan menjadi $0,5 \mathrm{~s}$ sehingga waku tripping relay menjadi agak lambat daripada setting waktu 0,05 s,ini dinamakan dengan karakteristik relay inverse time over current kurva Very Inverse. Kemudian setting waktu dibuat maksimum yaitu 1,0s dan menghasilkan kurva yang waktu tripping relay menjadi sangat lambat,ini dinamakan dengan karakteristikrelay inverse time over current kurva Extreme Inverse.

2. Persentase error

1.Arus Setting $2 \mathrm{~A}$

Tabel 2 Hasil Persentase error dengan arus setting 2A line " $R$ "

\begin{tabular}{|c|c|c|c|c|}
\hline \multirow{2}{*}{$\begin{array}{c}\text { I } \\
\text { Gangguan }\end{array}$} & \multirow{3}{*}{ TM } & $\begin{array}{c}\text { Waktu } \\
\text { Uji }\end{array}$ & $\begin{array}{c}\text { Waktu } \\
\text { Standart } \\
\text { BS142 }\end{array}$ & \% Error \\
\hline Ampere & Sekon & Sekon & $\%$ \\
\hline 4 & 0,05 & 0,924 & 0,75 & 23,2 \\
\hline 5 & 0,05 & 0,7 & 0,6 & 16,6667 \\
\hline 6 & 0,05 & 0,616 & 0,45 & 36,8889 \\
\hline 7 & 0,05 & 0,57 & 0,43 & 32,5581 \\
\hline 8 & 0,05 & 0,532 & 0,4 & 33 \\
\hline 9 & 0,05 & 0,512 & 0,35 & 46,2857 \\
\hline 4 & 0,5 & 6,408 & 5 & 28,16 \\
\hline 5 & 0,5 & 4,504 & 4,5 & 0,08889 \\
\hline 6 & 0,5 & 3,692 & 3 & 23,0667 \\
\hline 7 & 0,5 & 3,172 & 2,8 & 13,2857 \\
\hline 8 & 0,5 & 2,846 & 2,5 & 13,84 \\
\hline 9 & 0,5 & 2,636 & 2,2 & 19,818 \\
\hline 4 & 1 & 12,774 & 10 & 27,74 \\
\hline 5 & 1 & 8,714 & 8,5 & 2,52765 \\
\hline 6 & 1 & 7,052 & 6 & 17,5333 \\
\hline 7 & 1 & 6,076 & 5,5 & 10,4727 \\
\hline 8 & 1 & 5,428 & 5 & 8,56 \\
\hline 9 & 1 & 4,974 & 4,8 & 3,625 \\
\hline
\end{tabular}

Berdasarkan perhitungan yang dilakukan persentase error yang didapatkan masih belum tinggi.Persentase error tertinggi yaitu 46,28571\% dengan arus gangguan 9A pada TM 0,05 sedangkan persentase terendah yaitu $0,088889 \%$ dengan arus gangguan 5A pada TM 0,5. 2.Arus Setting 3A 
Tabel 3 Hasil Persentase error dengan arus setting 3A line "R"

\begin{tabular}{|c|c|c|c|c|}
\hline \multirow{2}{*}{$\begin{array}{c}\text { I } \\
\text { Gangguan }\end{array}$} & \multirow{3}{*}{ TM } & Waktu Uji & $\begin{array}{c}\text { Waktu } \\
\text { Standart } \\
\text { BS142 }\end{array}$ & \% Error \\
\cline { 1 - 5 } Ampere & Sekon & Sekon & $\%$ \\
\hline 4 & 0,05 & 2,384 & 1,9 & 25,4737 \\
\hline 5 & 0,05 & 1,064 & 0,9 & 18,2222 \\
\hline 6 & 0,05 & 0,824 & 0,75 & 9,86667 \\
\hline 7 & 0,05 & 0,702 & 0,68 & 3,23529 \\
\hline 8 & 0,05 & 0,63 & 0,55 & 14,5455 \\
\hline 9 & 0,05 & 0,592 & 0,45 & 31,5556 \\
\hline 4 & 0,5 & 19,278 & 16,5 & 16,8364 \\
\hline 5 & 0,5 & 8,008 & 8 & 0,1 \\
\hline 6 & 0,5 & 5,598 & 5 & 11,96 \\
\hline 7 & 0,5 & 4,452 & 4,2 & 6 \\
\hline 8 & 0,5 & 3,804 & 3,6 & 5,66667 \\
\hline 9 & 0,5 & 3,4 & 3 & 13,3333 \\
\hline 4 & 1 & 35,554 & 33,5 & 6,13134 \\
\hline 5 & 1 & 15,75 & 11,5 & 36,9565 \\
\hline 6 & 1 & 10,942 & 10 & 9,42 \\
\hline 7 & 1 & 8,614 & 8,5 & 1,34118 \\
\hline 8 & 1 & 7,342 & 7 & 4,88571 \\
\hline 9 & 1 & 0,524 & 6 & 8,73333 \\
\hline
\end{tabular}

Berdasarkan perhitungan yang dilakukan persentase error yang didapatkan masih belum tinggi.Persentase error tertinggi yaitu 36,95652\% dengan arus gangguan 5A pada TM 1,0 sedangkan persentase terendah yaitu $0,1 \%$ dengan arus gangguan $5 \mathrm{~A}$ pada TM 0,5 .

3.Arus Setting 4A

Tabel 4 Hasil Persentase error dengan arus setting 4A line "R"

\begin{tabular}{|c|c|c|c|c|}
\hline \multirow{2}{*}{$\begin{array}{c}\text { I } \\
\text { Gangguan }\end{array}$} & & $\begin{array}{c}\text { Waktu } \\
\text { Uji }\end{array}$ & $\begin{array}{c}\text { Waktu } \\
\text { Standart } \\
\text { BS142 }\end{array}$ & \% Error \\
\cline { 1 - 3 } Ampere & TM & Sekon & Sekon & $\%$ \\
\hline 5 & 0,05 & 2,712 & 2 & 35,6 \\
\hline 6 & 0,05 & 1,276 & 1 & 27,6 \\
\hline 7 & 0,05 & 0,932 & 0,8 & 16,5 \\
\hline 8 & 0,05 & 0,794 & 0,75 & 5,86667 \\
\hline 9 & 0,05 & 0,708 & 0,7 & 1,14286 \\
\hline 5 & 0,5 & 23,83 & 18,5 & 28,8108 \\
\hline 6 & 0,5 & 10,43 & 8,5 & 22,7059 \\
\hline
\end{tabular}




\begin{tabular}{|c|c|c|c|c|}
\hline \multirow{2}{*}{$\begin{array}{c}\text { I } \\
\text { Gangguan }\end{array}$} & & $\begin{array}{c}\text { Waktu } \\
\text { Uji }\end{array}$ & $\begin{array}{c}\text { Waktu } \\
\text { Standart } \\
\text { BS142 }\end{array}$ & \% Error \\
\cline { 1 - 4 } Ampere & TM & Sekon & Sekon & $\%$ \\
\hline 7 & 0,5 & 6,92 & 5,8 & 19,3103 \\
\hline 8 & 0,5 & 5,416 & 5 & 8,32 \\
\hline 9 & 0,5 & 4,562 & 4,2 & 8,61905 \\
\hline 5 & 1 & 55,07 & 53,5 & 2,93458 \\
\hline 6 & 1 & 21,092 & 17,8 & 18,4944 \\
\hline 7 & 1 & 13,816 & 11,3 & 22,2655 \\
\hline 8 & 1 & 10,572 & 10 & 5,72 \\
\hline 9 & 1 & 9,024 & 8,8 & 2,54546 \\
\hline
\end{tabular}

Berdasarkan perhitungan yang dilakukan persentase error yang didapatkan masih belum tinggi.Persentase error tertinggi yaitu 22,26549\% dengan arus gangguan 7A pada TM 1,0 sedangkan persentase terendah yaitu 1,142857\% dengan arus gangguan 9A pada TM 0,05.

\section{KESIMPULAN}

Pengujian NX203AIDMT Over Current Relay dapat disimpulkan bahwa :

a. Modul Praktikum yang telah dirakit dapat digunakan sesuai dengan fungsinya.

b. Pengujian dilakukan dengan menguji arus setting 2A; 3A; 4A, dengan waktu setting $(0,05 ; 0,5 ; 1) \mathrm{s}$ dan arus setting $2 \mathrm{~A}$ menghasilkan waktu tripping tercepat $0,502 \mathrm{~s}$ sedangkan arus setting 4A menghasilkan waktu tripping terlama 55,979s sesuai dengan karakteristik relay Relayinverse time over current yaitu semakin besar arus gangguan maka waktu tripping semakin cepat.

c. Kurva pengujian yang ditampilkan sama dengan kurva karakteristik inverse time over current relay yang berarti bahwa pengujian yang dilakukan terbukti kebenarannya dengan teori.

d. Pemasangan relayinverse time over current bertujuan untuk kontinuitas pelayanan pada konsumen tercapai.

e. Persentase error pengujian relay inverse time over current sebesar $66,67 \%$ maka dapat dikatakan bahwa relay masih dalam batas range toleransi yaitu $40 \%-120 \%$.

\section{DAFTAR PUSTAKA}

Abdul Mu'is, Sugianto. 2017.Perencanaan Sistem Distribusi Listrik Pelaksanaan Proyek Apartemen. Program Studi Teknik Elektro - ISTN 
Affandi, Irfan. 2009. Analisa Setting Relai Arus Lebih dan Relai Gangguan Tanah pada Penyulang Sadewa di GI Cawang. Skripsi Program Studi Teknik Elektro Kekhususan ElektroUniversitas Indonesia.

Chomarudin,Riki. 2018. Rele Proteksi pada Saluran Transmisi dan Gardu Induk. Universitas Gajah Mada

Hazairin, Samaulan. 2004. Dasar-Dasar Sistem Proteksi Tenaga Listrik. Unsri.

Muhalan,Yanto Husodo Budi. Jurnal Analisa Perhitungan dan Pengaturan Relai Arus Lebih dan Relai Gangguan Tanah pada Kubikel Cakra 20 kV di PT. XYZ, hal 166. ISSN: $1410-233$

NX203A IDMT Over Current Relay User's Guide

Sanzarian, Yogi.2015. Koordinasi Rele Arus Lebih dan Rele Gangguan Tanah Menggunakan Program Berbasis Electrical Transient And Analysis Program (ETAP) Pada Gardi Induk Bungaran Di PT. PLN. Politeknik negeri Sriwijaya Hal 17

Sarimun,Wahyudi.2012.Proteksi Sistem Distribusi Tenaga Listrik. Jawa Barat:Garamond TEMI TIMOTIUS D. NGEDI.2016.Pengggunaan Over Current Relay Dalam System Tenaga Listrik.UNIVERSITAS NUSACENDANA. 